\title{
PLANO DE DESENVOLVIMENTO ESTADUAL SUSTENTÁVEL E 0 NOVO PARADIGMA DE DESENVOLVIMENTO PARA A AMAZÔNIA
}

\section{CLEVERTON REIKDAL}

Doutor em Ciências Jurídicas, Universidade do Vale do Itajaí - UNIVALI, Brasil.

Professor em Direito na Faculdade Católica de Rondônia.

tom.reik@gmail.com

\section{OSMAR SIENA}

Doutor em Engenharia de Produção, Universidade Federal de Santa Catarina - UFSC, Brasil.

Professor em Direitos Humanos e Desenvolvimento da Justiça, Universidade Federal de Rondônia - UNIR, Brasil.

osmar_siena@uol.com.br

\section{Resumo}

O trabalho visou identificar o alinhamento do Plano de Desenvolvimento Estadual Sustentável de Rondônia com a proposta de um novo paradigma de desenvolvimento para a Amazônia proposto por Carlos Afonso Nobre e colaboradores, o qual tem por base a valorização dos produtos da biodiversidade para o curto prazo como uma fase de transição e, no longo prazo, as tecnologias disruptivas emergentes da quarta revolução industrial. 0 pressuposto é que os modelos atuais de desenvolvimento da região não são capazes de responder aos problemas e impedir o aumento da degradação ambiental. Foi realizada uma pesquisa classificada como descritiva, documental, com adoção do método qualitativo. Os dados foram retirados do texto do PDES-2015 e submetidos a análise do conteúdo. Constatou-se que o referido plano, mesmo possuindo projetos voltados para um desenvolvimento sustentável, abarcando as esferas ambiental, social, econômica e cultural, reforçam o paradigma atual da visão de apropriação apenas econômica da floresta.

Palavras-chave: paradigma, desenvolvimento sustentável, políticas públicas. 


\title{
SUSTAINABLE STATE DEVELOPMENT PLAN AND THE NEW DEVELOPMENT PARADIGM FOR THE AMAZÔNIA
}

\begin{abstract}
The aim of this study was to identify the alignment of the Rondônia State Sustainable Development Plan (PDES) with the proposal of a new development paradigm for the Amazon proposed by Carlos Afonso Nobre and employees, based on valorization of short-term biodiversity products as a period of transition, in the long term, the disruptive technologies emerging from the fourth industrial revolution. The assumption is that current models of development in the region are not able to respond to problems and prevent the increase of environmental degradation. A research was classified as descriptive, documentary, with the adoption of the qualitative method. The data were taken from the PDES-2015 text and submitted to content analysis. It was verified that the plan, even having projects aimed at sustainable development, encompassing the environmental, social, economic and cultural spheres, the programs reinforce the current paradigm of the vision of economic ownership of the forest.
\end{abstract}

Keywords: paradigm, sustainable development, public policy.

\section{PLAN DE DESARROLLO ESTADUAL SOSTENIBLE Y EL NUEVO PARADIGMA DE DESARROLLO PARA LA AMAZÔNIA}

\begin{abstract}
Resumen
El trabajo tuvo como objetivo identificar la convergencia del Plan de Desarrollo Estadual Sostenible de Rondônia (PDES) con la propuesta de un nuevo paradigma de desarrollo para la Amazônia, desarrollada por Carlos Afonso Nobre y colaboradores, baseada en la valorización de los productos de la región, la biodiversidad a corto plazo como una fase de transición y, a largo plazo, las tecnologías disruptivas emergentes de la cuarta revolución industrial. La suposición es que los modelos actuales de desarrollo de la región no son capaces de responder a los problemas que se presentan, ni impedir el aumento de la degradación ambiental. Se realizó una investigación clasificada como descriptiva, documental, con adopción del método cualitativo. Los datos fueron retirados del texto del PDES-2015 y sometidos a análisis del contenido. Se constató que dicho plan, aun teniendo proyectos orientados hacia un desarrollo sostenible, abarcando las esferas ambiental, social, económica y cultural, sus programas refuerzan el paradigma actual de la visión de apropiación apenas económica del bosque.
\end{abstract}

Palabras clave: paradigma, desarrollo sostenible, políticas públicas. 


\section{INTRODUÇÃO}

Um dos grandes desafios que o desenvolvimento dito sustentável enfrenta é a lógica do mercado liberal, a qual requer ausência ou o mínimo de controle para que suas próprias forças possam Ihe regular. A incompatibilidade entre o que o mercado pode oferecer e o que necessita a sociedade requer a presença e planejamento por parte do Estado (Sachs, 2009). O Estado, nessa direção, pode intervir por meio da criação de políticas públicas que visem modificar a cultura produtiva.

As políticas públicas nacionais possuem em seus projetos e perspectivas o objetivo de correlacionar os elementos do ambiente natural, sociedade, economia e cultura. No Brasil, verifica-se que inicialmente foi estruturado um sistema de comando e controle com o estabelecimento de normas, especialmente do controle da poluição das empresas, para, posteriormente, incluir na agenda programas para reduzir os impactos sociais e ambientais decorrentes do processo de colonização (Nascimento, Silva \& Santos, 2014).

A expansão da incorporação dos preceitos do desenvolvimento sustentável em diversas áreas da administração pública ocorre em razão da necessidade de contemplá-lo na seleção e implementação de políticas públicas (Nobre, Sampaio, Borma, Castilla-Rubio, Silva \& Cardoso, 2016; Ollaik \& Medeiros, 2011; Sachs, 2009). No Brasil, esta incorporação encontra interesse regional, nacional e internacional na proteção e desenvolvimento da região amazônica por se enquadrar como um patrimônio público relevante. O país detém em torno de 15 a 20\% da biodiversidade terrestre, constituindo uma das regiões mais ricas do planeta (Pedrini, 2006). 0 ecossistema amazônico tem importância local e global, pois nele tem grande concentração da riqueza biológica. As precipitações fluviais contribuem para controle da temperatura da atmosfera terrestre, que somada a sua dinâmica fluvial, deságua no mar mais de 200 mil metros cúbicos de água fresca nos oceanos; sua reserva de carbono é de aproximadamente 150 a 200 bilhões de toneladas; e socialmente detém em sua região uma diversidade etnológica e de linguagem das comunidades tradicionais (Nobre, Sampaio, Borma, Castilla-Rubio, Silva \& Cardoso, 2016). Apesar dessa riqueza, os modelos que dominam historicamente o desenvolvimento da região amazônica são fundamentados em: i) impedimento legal de exploração humana em regiões de conversão ambiental total e ii) degradação da floresta para o aumento da produção em larga escala de proteínas, extração de madeiras e uso dos rios e bacias hidrográficas para a criação de energia hidrelétrica (Nobre, Sampaio, Borma, Castilla-Rubio, Silva \& Cardoso, 2016).

Em uma análise comparativa entre os indicadores de desmatamento e crescimento econômico dos estados da Amazônia brasileira, Nobre, Sampaio, Borma, Castilla-Rubio, Silva \& Cardoso (2016) verificaram que enquanto a região necessita de 750 mil $\mathrm{km} 2$ para produzir $15 \%$ do total da produção agrícola nacional, o Estado de São Paulo representa 11,3\%, valendo-se de um espaço de 193 mil km2. Para os referidos autores, esses dados indicam que nos últimos 50 anos os modelos adotados não resultaram em aumento da produtividade e da qualidade de vida para aqueles que vivem na região amazônica e representam perigo para a manutenção do equilíbrio ambiental, social e econômico da região. Assim, os dois modelos atuais não são mais suficientes para justificar o baixo desenvolvimento econômico e social e o alto impacto ambiental, havendo necessidade de um novo caminho (Nobre, Sampaio, Borma, Castilla-Rubio, Silva \& Cardoso, 2016). Por isso, advogam a adoção de um novo paradigma de desenvolvimento que esteja além de "... comando e controle de medidas para impedir o desmatamento ilegal... o desafio, portanto, é reconciliar o presente modelo de desenvolvimento com um novo paradigma de desenvolvimento sustentável da Amazônia" (Nobre, Sampaio, Borma, Castilla-Rubio, Silva \& Cardoso, 2016, p.10760). Este novo paradigma tem como base o desenvolvimento de novas tecnologias e produtos a partir do ativo biológico da floresta, sem que para isso seja necessário mais desmatamento. 
No Estado de Rondônia, localizado na Região Norte do país, cujo território é considerado integralmente como Região Geoeconômica da Amazônia ou Complexo Regional Amazônico (Becker, 2001), refletindo o que ocorre em boa parte da região, as políticas públicas de desenvolvimento econômico têm como base a demanda pela agricultura de commodities, com instituições com fraco poder e a ampla infraestrutura energética (Nobre, Sampaio, Borma, CastillaRubio, Silva \& Cardoso, 2016). Como consequência, os riscos de incremento do desmatamento e de desequilíbrios ambientais ainda são possíveis. Na perspectiva da sustentabilidade, o Governo do Estado de Rondônia lançou em 2015 o Plano de Desenvolvimento Estadual Sustentável de Rondônia (PDES) com objetivo de "... refletir as orientações, estratégias e diretrizes da Política Nacional de Desenvolvimento Regional, considerando o diagnóstico estadual em suas particularidades históricas e estruturais, assim como em suas potencialidades, tendências e gargalos" (PDES-2015, 2015, p.87), buscando, inclusive, praticar atos embasados em um novo paradigma de sustentabilidade ambiental (PDES-2015, 2015).

Diante deste contexto, este trabalho discute a extensão e a potencialidade do atual PDES de Rondônia em relação a esta nova perspectiva de desenvolvimento, identificando as lacunas relacionadas à falta de coesão com os pressupostos do novo paradigma discutido por Nobre, Sampaio, Borma, Castilla-Rubio, Silva \& Cardoso (2016). Assim, o objetivo geral da pesquisa é identificar o alinhamento do Plano de Desenvolvimento Estadual Sustentável de Rondônia (PDES2015, 2015) com a proposta de um novo paradigma de desenvolvimento para a Amazônia proposto por Nobre, Sampaio, Borma, Castilla-Rubio, Silva \& Cardoso (2016).

A pesquisa contribui para avanço das discussões sobre implementação de políticas públicas na perspectiva do desenvolvimento sustentável. Como contribuição prática, ao apresentar sugestões de possiveis aperfeiçoamentos do Plano, o estudo contribui para discussão sobre qual o caminho do desenvolvimento sustentável para o estado de Rondônia e Amazônia brasileira.

Este artigo está organizado em cinco partes, além desta introdução: a exposição da base teórica, o contexto do estudo, os aspectos metodológicos, os resultados e sugestões e as considerações finais.

\section{NOVO PARADIGMA PARA DESENVOLVIMENTO DA AMAZÔNIA}

A realização do desenvolvimento sustentável cabe às esferas privada e pública. O governo tem a responsabilidade em trazer à tona o debate sobre o tema e a criação de políticas públicas para alcançar os resultados deste desenvolvimento com proteção às riquezas e ao meio ambiente para as gerações atuais e futuras (Sachs, 2009). A expansão da incorporação dos preceitos do desenvolvimento sustentável em diversas áreas da administração pública ocorre em razão da necessidade de contemplá-los na seleção e implementação de políticas públicas (Nobre, Sampaio, Borma, Castilla-Rubio, Silva \& Cardoso, 2016; Ollaik \& Medeiros, 2011; Sachs, 2009). A inserção do tema na agenda é apenas uma das etapas; há também a necessidade de verificar as soluções e alternativas apresentadas por meio de processos avaliativos dos instrumentos selecionados para a política escolhida.

Em relação às políticas públicas refletidas nos modelos de ocupação da região amazônica, reconhece-se um comportamento padrão acerca do desmatamento (Ferreira, Venticinque \& Almeida, 2005), com consequência para a região e para todo o planeta. O relatório publicado em 2008 sobre as mudanças climáticas globais aponta a emissão de gás carbônico decorrente dos desmatamentos das florestas tropicais como causa do aquecimento global (Nobre, 2008). E o desmatamento na Amazônia é fator importante neste cenário. O referido autor defende que é "... perfeitamente possivel reduzir os desmatamentos da floresta amazônica a valores próximos de zero, uma vez que existe um gigantesco estoque de áreas improdutivas, degradadas ou abandonadas em todo o país" (p.16). Em estudo mais recente, Nobre, Sampaio, Borma, Castilla-

OS, Organizações e Sustentabilidade, 8(1), p. 124-140, Londrina, PR, jan./jun. 2020. 
Rubio, Silva \& Cardoso (2016), ao analisarem a redução do desmatamento entre 2004 e 2009 e o crescimento da produção agrícola da região no mesmo período, concluem que é possível o aumento da produção na região com diminuição da taxa de desmatamento. É necessário reconhecer que a redução da floresta não decorre apenas em razão do desmatamento provocado diretamente pelo homem, mas também das consequências climáticas que os modelos de desenvolvimento provocam e que existe correlação entre o equilíbrio hídrico, climático e a vegetação da floresta (Nobre, Sampaio, Borma, Castilla-Rubio, Silva \& Cardoso, 2016).

0 desmatamento da região entre os anos de 1989 a 2003, com índice inicial em torno de $14 \mathrm{mil} \mathrm{km} 2$ e final de 25 mil km2, está relacionado com a dinâmica da construção de rodovias, do mercado de exportação da madeira e agropecuária (Ferreira, Venticinque \& Almeida, 2005). De acordo com os mesmos autores, a partir de 2004, começa-se a apresentar uma redução do desmatamento na região em razão da intervenção de órgãos de controle e programas de distribuição de renda, com redução efetiva do desmatamento para $7 \mathrm{mil} \mathrm{km2} \mathrm{no} \mathrm{ano} \mathrm{de} \mathrm{2009.} \mathrm{Porém,} \mathrm{ao} \mathrm{atualizar} \mathrm{estes} \mathrm{dados}$ para 2017, verifica-se no ano de 2016 um aumento do desmatamento em 27\% em relação ao ano de 2015, quando havia sido identificado 6.207 km2 (INPE, 2017). A floresta amazônica já sofreu perda de mais de 1 milhão de quilômetros quadrados em razão do desmatamento e pode continuar a perder ainda mais se continuar no modelo de 'proteção integral' versus modelo tradicional de agricultura e expansão da geração de energia hidrelétrica (Nobre, Sampaio, Borma, Castilla-Rubio, Silva \& Cardoso 2016). Como a base do desenvolvimento da região ainda se mantém, os riscos de incremento do desmatamento são reais. Esta realidade reflete os modelos que dominaram historicamente o desenvolvimento da região: i) impedimento legal de exploração humana em regiões de conversão ambiental total e ii) degradação da floresta para o aumento da produção em larga escala de proteínas, extração de madeiras e uso dos rios e bacias hidrográficas para a criação de energia hidrelétrica. Considerando a possibilidade de que retornem os altos índices de desmatamento, Nobre, Sampaio, Borma, Castilla-Rubio, Silva \& Cardoso (2016) advogam a necessidade de um novo paradigma de desenvolvimento para a região para superar os modelos atuais. Os referidos autores propõem a superação a partir do curto e do longo prazo. Em curto prazo é possível desenvolver uma cadeia de produtos únicos advindos da biodiversidade da Amazônia, como o babaçu, açaí, jambu, óleo da andiroba e copaíba, entre outros, e com a agregação de valores para conquistar o mercado; e, em uma perspectiva de longo prazo, aprender com a floresta amazônica, como ela se comporta enquanto um sistema vivo e de geração de energia. Nesta segunda perspectiva, será exigida a participação de capital de risco para fomentar a pesquisa de ponta e desenvolver novos designs advindos das tecnologias decorrentes da Quarta Revolução Industrial. Essas novas tecnologias são reconhecidas como aquelas que promovem alteração e mudança profunda sobre as inovações atuais (Schwab, 2016), com possibilidades de gerar novos designs com capacidade de recriar a inteligência da natureza de forma artificial com projetos tecnológicos que poderão emular as formas naturais, permitindo, por exemplo, criar modelos de produção de energia mais sustentáveis. Essas novas formas de geração de energia e os aparatos que ensinarão como os sistemas biológicos funcionam terão como base os novos produtos desenvolvidos a partir da alta tecnologia. Será possivel e necessário aprender com a natureza.

As recentes pesquisas acerca dos produtos da biodiversidade podem ter na ciência e na tecnologia indutores do desenvolvimento regional e nacional. As potencialidades deste desenvolvimento estão atreladas a um campo multidisciplinar, englobando atividades manuais dos extratores, atividades intelectuais de desenvolvimento de novas tecnologias (pesquisas e desenvolvimento), relações jurídicas internas e externas, atividades econômicas e comerciais nacionais e internacionais e atividades de transferência tecnológica (Russo, Silva \& Nunes, 2012; Silva, Albuquerque \& Amaral, 2017). A proposta de exploração dos produtos da biodiversidade foi eleita por Nobre, Sampaio, Borma, Castilla-Rubio, Silva \& Cardoso (2016) como uma forma de superar 0

OS, Organizações e Sustentabilidade, 8(1), p. 124-140, Londrina, PR, jan./jun. 2020.

ISSN 2318-9223, http://www.uel.br/revistas/uel/index.php/ros/issue/view/1634/showToc 
paradigma atual a curto prazo, identificando ser possivel desenvolver cadeias de produtos únicos advindos da biodiversidade da Amazônia e com a agregação de valor para conquistar mercado. Uma das críticas apontadas pelo baixo desenvolvimento dos produtos da sociobiodiversidade refere-se a uma visão da região que não consegue diferenciar e qualificar a diversidade da biomassa amazônica: "O modelo econômico existente na região amazônica, pode-se dizer, ignora e menospreza a diversidade dos inúmeros ecossistemas. Na realidade a Amazônia brasileira tem sido considerada nos planos governamentais como um sistema natural homogêneo" (Pedrozo, Silva, Sato \& Oliveira, 2011, p.96). Estes produtos estão relacionados com a economia da subsistência das comunidades em razão de serem localizados e produzidos nas unidades de conservação e outras áreas de proteção e amplamente aceitos no comércio local. Assim, possuem papel especial também na sua exploração mediante os Arranjos Produtivos Locais (APL) e podem contribuir para o desenvolvimento sustentável da região tendo em vista suas características sistêmicas, as quais envolvem uma cadeia de processos realizados por diversos atores, produtores locais, indústrias, entidades associativas e públicas.

Em uma perspectiva de longo prazo pode-se aprender e desenvolver com a floresta amazônica, mediante o uso de altas tecnologias inovadoras, descobrindo como ela se comporta enquanto um sistema vivo, criando sistemas ambientalmente amigos, tecnologias de prevenção, designs têxteis, substituição de matéria prima, produção de energia e cognição via inteligência artificial (Nobre, Sampaio, Borma, Castilla-Rubio, Silva \& Cardoso 2016). Existe neste caminho forma de superar os modelos atuais de desenvolvimento por meio da aplicação que engloba uma combinação de avançadas tecnologias digital, material e biológica (Nobre, Sampaio, Borma, Castilla-Rubio, Silva \& Cardoso 2016); aprender com a natureza é uma política ecológica capaz de superar o paradigma hegemônico, constituindo novos relacionamentos entre a sociedade e a natureza (Iguarán \& Hernández, 2016). A biomimese, por exemplo, tem como base aprender com a natureza e, com o desenvolvimento tecnológico digital, aplicar este conhecimento em designs que a imitam; a biomimese “... propone una reconstrucción de la tecnosfera tomando como modelo de inspiración la naturaliza" (Iguarán \& Hernández, 2016, p.24).

A quarta revolução industrial é uma evolução histórica e científica das revoluções industriais que modificam de forma abrupta e radical as estruturas sociais e econômicas, possibilitando o aumento da produção humana "... por meio da potência aprimorada da cognição" (Schwab, 2016, p.15). 0 que impulsiona a quarta revolução industrial são as várias tecnologias já desenvolvidas que agora criam inovações aproveitando-se da capacidade de disseminação da digitalização e da tecnologia da informação. A relevância destes estudos baseados na inserção da tecnologia avançada para aprender com a natureza reside na superação da visão dos ecossistemas como reservas extrativistas ou de fornecimento de matéria prima, e os identificar "... como modelos referenciales de actividad e interacción metabólica circular y auto-sostenible susceptibles de ser aplicados y transferidos a diferentes contextos sociales" (Sierra, 2016, p.65). Estas inovações tecnológicas a serem aplicadas na região amazônica somente podem ser realizadas em razão do aprendizado que o homem vem tendo a partir da revolução digital e a sua aplicação no desenvolvimento da ciência e tecnologia (Schwab, 2016).

\section{OESTADO DE RONDÔNIAE O PDES-RO}

A história rondoniense é marcada pelos ciclos da estrada de ferro, da borracha, da agricultura, expansão das rodovias transnacionais, criação de gado e exploração de minério. Esses ciclos serviram como meios de ocupação da região pelos brasileiros para evitar invasões estrangeiras, como foi o caso do Plano de Integração Nacional, complementado pelo Programa de Redistribuição de Terras e de Estímulo à Agroindústria do Norte e do Nordeste (PROTERRA) e do Plano de Polos Agropecuários e Agro Minerais para a criação de gado e exploração mineral na região, o

OS, Organizações e Sustentabilidade, 8(1), p. 124-140, Londrina, PR, jan./jun. 2020.

ISSN 2318-9223, http://www.uel.br/revistas/uel/index.php/ros/issue/view/1634/showToc 
POLAMAZONIA (Pedlowski, Dale, Matricardi \& Silva Filho, 1997). As formas de ocupação por assentamentos humanos ocorreram em razão da exploração dos recursos naturais da região, como o ciclo da extração da borracha, os assentamos agrícolas e, principalmente, a descoberta da cassiterita na região nos anos 50 (Pedlowski, Dale, Matricardi \& Silva Filho,1997). Posteriormente a construção de rodovias também teve importante relevância e nas últimas décadas a exploração dos rios para implementação das usinas hidrelétricas.

A década de 1970 ficou marcada como o início do ciclo exploratório intensivo da região, em contemporaneidade com um pensamento sobre o desenvolvimento na era do meio ambiente (Sachs, 2009); por outro lado, os projetos de colonização intensificados pelo Programa de Integração Nacional (PIN) trouxeram, junto com as soluções de divisão de terra, problemas ambientais. A partir deste período, a devastação da floresta se intensifica. Os assentamos agrícolas foram realizados por pequenos agricultores vindos de outras regiões e por grandes fazendas de gado, principalmente na região central do Estado (Pedlowski, Dale, Matricardi \& Silva Filho, 1997).

Visando a integração da região com as demais regiões nacionais, o Programa Integrado de Desenvolvimento do Noroeste do Brasil (POLONOROESTE) foi criado em 1981 e teve como uma das metas a pavimentação da rodovia BR 364, ligando Cuiabá a Porto Velho. Entre as críticas destinadas ao governo federal em relação a este Programa, está a da ausência de conhecimento da ecologia local, pois os projetos de construção da rodovia trouxeram impactos inesperados por sua ocupação desordenada, desmatamento acelerado e invasão das reservas florestais e terras indígenas (Ferreira, Araújo \& Marques, 2006). Assim, no ano de 1992 foi estabelecido o Plano Agropecuário e Florestal de Rondônia (PLANAFLORO) “... para dar seguimento e aperfeiçoar programas especiais de investimento, a exemplo do Poloamazônia, e procurando corrigir os impactos ambientais negativos do Polonoroeste, bem como realizar grandes investimentos públicos em infraestrutura e fortalecimento institucional do setor público e de setores nãogovernamentais" (Ferreira, Araújo \& Marques, 2006, p. 402). O PLANAFORO tinha, também, entre suas prioridades realizar o Zoneamento Socioeconômico-Ecológico (ZSEE), o qual estava relacionado com a política pública do governo federal que, no início dos anos 1990, adota a ideia de Zoneamento Econômico-Ecológico (Santana, 2007). Visando qualificar as peculiaridades da região do Estado de Rondônia, desenvolveu-se nesta política a distribuição do Estado em zonas específicas para a utilização dos seus ecossistemas de forma balanceada, o Zoneamento Socioeconômico-Ecológico (ZSEE). A elaboração da primeira ZSEE ocorreu entre 1986 e 1988, já a segunda foi estabelecida no ano de 2000, mediante a Lei complementar $n^{\circ} 233$ do ano de 2.000. Em 2017, o Estado promove a atualização da $2^{a}$ aproximação ZSEE.

Como política pública para integrar e ampliar o reconhecimento dos impactos ambientais e mitigar seus efeitos para a geração atual e futura, o Plano de Desenvolvimento Estadual Sustentável de Rondônia (PDES-2015, 2015), que está em vigência desde 2015 e terá a duração de 15 anos, é sequência de outros Planos e programas que foram criados no Estado. Este plano criou programas supostamente para desenvolver práticas mais sustentáveis para o desenvolvimento de Rondônia, respeitando a floresta e os povos locais. 0 macro objetivo do plano é "... refletir as orientações, estratégias e diretrizes da Política Nacional de Desenvolvimento Regional, considerando o diagnóstico estadual em suas particularidades históricas e estruturais, assim como em suas potencialidades, tendências e gargalos" (PDES-2015, 2015, p.87). Este objetivo macro é orientado mediante os objetivos estratégico, geral e específicos. 0 estratégico está relacionado a utilização de conhecimento da realidade regional e nas políticas públicas voltadas ao desenvolvimento socioeconômico; o objetivo geral visa propiciar condições para reduzir as desigualdades sociais e valorizar os recursos locais; por fim, o PDES possui objetivos específicos separados em quatorze itens delimitados por temas específicos.

OS, Organizações e Sustentabilidade, 8(1), p. 124-140, Londrina, PR, jan./jun. 2020. 
Visando alcançar o desenvolvimento sustentável na complexidade das esferas ambiental, econômica, social e de gestão pública, na elaboração do PDES foi realizado um diagnóstico da relação entre os produtores e o papel do governo, identificando as potencialidades e os gargalos. Com base nestes resultados e nas diretrizes do Plano Nacional de Desenvolvimento Regional (PNDR), o PDES se estruturou em quatro diretrizes estratégias:

- $\quad$ Diretriz I - Territorialização e Gestão Ambiental, que abarca a abordagem territorial, a gestão ambiental e a sustentabilidade;

- $\quad$ Diretriz II - Bem-Estar Social, que envolve a ação do Estado na promoção e acesso aos serviços públicos de forma oportuna e de qualidade.

- Diretriz III - Competividade Sustentável, envolvendo a dotação de infraestrutura logística e o fomento do desenvolvimento econômico inclusive, com base nos ativos regionais;

- Diretriz IV - Modernização da Gestão Pública, que objetiva instituir mecanismos de governança e gestão de excelência na condução da administração pública e no planejamento do desenvolvimento estadual.

Cada uma dessas diretrizes é composta por uma matriz de programas, projetos e indicadores que servirão para a avaliação periódica, selecionados a partir das orientações estratégias elaboradas. Os programas pertencentes a cada uma dessas diretrizes, por sua vez, são compostos por uma ou mais ações e para cada um desses programas há um objetivo específico a ser atingido.

\section{PROCEDIMENTOS METODOLÓGICOS}

Considerando as limitações de espaço para este artigo, foi necessário fazer um recorte. Assim, a análise do PDES relatada neste trabalho focou na terceira Diretriz, da Competividade Sustentável, por ser aquela de cunho produtivo e econômico.

A pesquisa é classificada como descritiva, documental, com adoção do método qualitativo. Os dados foram retirados do texto do PDES-2015 e submetidos a análise do conteúdo na sua vertente qualitativa, conforme os preceitos de Bardin (2004). A análise foi a base para inferir se os programas, projetos e indicadores possuem características de um desenvolvimento que busca atingir ou não um novo paradigma. Com a interpretação dos resultados a partir da análise de conteúdo, pretendeu-se superar a visão mais restrita positivista e ampliar o seu campo de visão, aplicando-se os pressupostos da pesquisa de cunho qualitativo na área da administração (Mozzato \& Grybovski, 2011). A análise de conteúdo é uma técnica cujo objeto do estudo é o registro em si presente no documento e pode ser utilizada na pesquisa qualitativa quando se requer buscar a presença ou ausência de características relacionadas a um determinado dado (Bardin, 2004).

Considerando os objetivos da pesquisa, a análise realizada separou os programas da Terceira Diretriz em dois grandes grupos: aqueles que estão relacionados à superação dos modelos atuais de desenvolvimento da Amazônia no seu viés de curto prazo e aqueles que estão associados ao alcance do novo paradigma no longo prazo. Os primeiros são programas relacionados a produtos da biodiversidade ou outras atividades de baixo impacto sobre o ambiente natural. Os segundos dizem respeito à busca do desenvolvimento sustentável regional a partir da aplicação de novos designs advindos da quarta revolução industrial. Os programas estão listados no quadro 1.

QUADRO 1 - PDES-2015 - PROGRAMAS DA DIRETRIZ III - COMPETIVIDADE SUSTENTÁVEL

\begin{tabular}{|l|l|}
\hline \multicolumn{1}{|c|}{ Programas de Curto Prazo } & \multicolumn{1}{|c|}{ Programas de Longo Prazo } \\
\hline $\begin{array}{l}\text { 1. Programa Estratégico de Desenvolvimento de APL no } \\
\text { Estado. }\end{array}$ & 2. Desenvolvimento da Bovinocultura de Corte. \\
\hline
\end{tabular}

OS, Organizações e Sustentabilidade, 8(1), p. 124-140, Londrina, PR, jan./jun. 2020.

ISSN 2318-9223, http://www.uel.br/revistas/uel/index.php/ros/issue/view/1634/showToc 
Plano de Desenvolvimento Estadual Sustentável e o Novo Paradigma de Desenvolvimento para a Amazônia

\begin{tabular}{|c|c|}
\hline 4. Fortalecimento da Agricultura Familiar. & 3. Desenvolvimento da Bovinocultura de Leite \\
\hline 6. Apoio à Aquicultura & $\begin{array}{l}\text { 5. Transição para a Agropecuária de Baixa Emissão de } \\
\text { Carbono. }\end{array}$ \\
\hline 8. Apoio à Lavoura Cacaueira & 7. Programa de Apoio à Lavoura Cafeeira \\
\hline $\begin{array}{l}\text { 11. Apoio e Fomento à Produção Sustentável e } \\
\text { Industrialização de Produtos da Sociobiodiversidade }\end{array}$ & $\begin{array}{l}\text { 9. Apoio ao Fortalecimento da Cadeia Produtiva da } \\
\text { Soja. }\end{array}$ \\
\hline $\begin{array}{l}\text { 14. Promoção da Cultura e Apoio ao Desenvolvimento da } \\
\text { Economia Criativa. }\end{array}$ & $\begin{array}{l}\text { 10. Ordenamento e Fomento à Sustentabilidade no } \\
\text { Setor Madeireiro. }\end{array}$ \\
\hline \multirow[t]{3}{*}{ 15. Promoção do Turismo } & 12. Desenvolvimento da Indústria. \\
\hline & 13. Desenvolvimento e Consolidação do Setor Mineral \\
\hline & 16. Infraestrutura Logística \\
\hline
\end{tabular}

Fonte: Elaborado pelos autores com base no PDES-2015 (2015).

As categorias e respectivos fatores de análise foram selecionados mediante a inferência realizada a partir do referencial teórico discutido, conforme quadro 2.

A presença de cada categoria tem a capacidade de, em conjunto com as demais, proporcionar, em tese, a superação dos modelos atuais em alcançar um novo modelo de desenvolvimento sustentável na região. Mediante a técnica adotada, portanto, se realizou não apenas uma descrição do conteúdo do PDES, mas também uma comparação entre o conteúdo e a busca por um novo paradigma de desenvolvimento da região baseado na agregação de valores aos produtos e na necessidade intrínseca da existência da floresta para o desenvolvimento da região amazônica.

QUADRO 2 - CATEGORIA DE ANÁLISE

\begin{tabular}{|c|c|}
\hline \multicolumn{2}{|r|}{ Categorias para Análise de Curto Prazo } \\
\hline Categoria & Fatores de Análise \\
\hline $\begin{array}{l}\text { 1) Investimento e } \\
\text { modificações nas } \\
\text { estruturas sociais, } \\
\text { econômicas e políticas da } \\
\text { valorização dos produtos } \\
\text { da biodiversidade. }\end{array}$ & $\begin{array}{l}\text { 1.1) Investimento financeiro na identificação e exploração dos produtos da biodiversidade; } \\
\text { 1.2) desenvolvimento tecnológico para a exploração dos produtos da biodiversidade; } 1.3 \text { ) } \\
\text { superação do uso comercial de produtos decorrentes da exploração de commodities pelos } \\
\text { produtos da biodiversidade; 1.4) aprimoramento na qualidade final dos produtos da } \\
\text { biodiversidade; } 1.5 \text { ) aumento da identificação da variedade de produtos da biodiversidade } \\
\text { e do potencial de exploração de cada um destes; } 1.6 \text { ) marketing nacional e internacional } \\
\text { da capacidade comercial e produtiva de cada produto, na sua especificidade; } 1.7 \text { ) } \\
\text { Modificações nas estruturas sociais, econômicas e políticas da valorização dos produtos } \\
\text { da biodiversidade e da agricultura familiar }\end{array}$ \\
\hline $\begin{array}{l}\text { 2) Incentivo e valorização } \\
\text { dos produtos com baixo } \\
\text { impacto no sistema } \\
\text { amazônico }\end{array}$ & $\begin{array}{l}\text { 2.1) identificação dos impactos ambientais, econômicos e sociais da exploração dos } \\
\text { produtos da sociobiodiversidade e da agricultura familiar; } 2.2 \text { ) desenvolvimento da } \\
\text { agricultura familiar sustentável; }\end{array}$ \\
\hline $\begin{array}{l}\text { 3) Benefícios para } \\
\text { populações regionais }\end{array}$ & $\begin{array}{l}\text { 3.1) Impactos na qualidade de vida do sucesso na explor } \\
\text { população local; 3.2) indicadores específicos para mensurar } \\
\text { nos produtos da sociobiodiversidade e atividades de baixo ir } \\
\text { a floresta tropical. }\end{array}$ \\
\hline \multicolumn{2}{|r|}{ Categorias para Análise de Longo Prazo } \\
\hline Categoria & \\
\hline $\begin{array}{l}\text { 1) Inovação com base em } \\
\text { tecnologia }\end{array}$ & $\begin{array}{l}\text { 1.1) investimento financeiro em pesquisa para o desenvolvimento comercial de } \\
\text { tecnologias disruptivas; } 1.2 \text { ) pesquisas para aplicar as tecnologias digitais existentes para } \\
\text { promover a aproximação das populações locais aos grandes centros nacionais e } \\
\text { internacionais. 1.3) Novos produtos baseados no aprendizado com a floresta. }\end{array}$ \\
\hline $\begin{array}{l}\text { 2) Investimento de capital } \\
\text { de risco. }\end{array}$ & $\begin{array}{l}\text { 2.1) investimento financeiro privado de risco para criação de novas formas de geração e } \\
\text { reserva de energia; } 2.2 \text { ) investimento de recursos financeiros para desenvolver novos } \\
\text { produtos sem aumentar a exploração dos recursos já utilizados para a atividade } \\
\text { econômica. }\end{array}$ \\
\hline $\begin{array}{l}\text { 3) Reformulação da } \\
\text { produção baseada na } \\
\text { integralidade da floresta. }\end{array}$ & $\begin{array}{l}\text { 3.1) indicadores de desmatamento zero; 3.2) desenvolvimento de técnicas agropecuárias } \\
\text { que reduzam os impactos ambientais das atividades agropecuárias; 3.3) promoção de } \\
\text { educação sobre as relações de capacidade e necessidade de produção e consumo, política } \\
\text { do consumo sustentável. }\end{array}$ \\
\hline
\end{tabular}

Fonte: Elaborado pelos autores com base com base em Nobre, Sampaio, Borma, Castilla-Rubio, Silva \& Cardoso (2016), Nobre (2008), Pedrozo, Silva, Sato \& Oliveira (2011), Schwab (2016), Iguarán e Hernández (2016).

OS, Organizações e Sustentabilidade, 8(1), p. 124-140, Londrina, PR, jan./jun. 2020.

ISSN 2318-9223, http://www.uel.br/revistas/uel/index.php/ros/issue/view/1634/showToc 


\section{RESULTADOS E DISCUSSÃO}

A análise realizada neste trabalho focou na parte relativa da Competividade Sustentável, representada pela Terceira Diretriz do PDES. Nesta, existe o reconhecimento que há uma crescente demanda por alimentos e matérias primas para alimentar a sociedade e indústria e se vislumbra que atender as referidas demandas a partir do comércio de commodities ou exploração que importe em desmatamento não é o caminho mais adequado. Apontam os idealizadores do plano que não se deve buscar um padrão de crescimento baseado em commodites nestas regiões menos desenvolvidas do país, visto que "... tratam-se de produtos intensivos em recursos naturais, que agregam baixo valor, promovem elevada pressão ambiental e distribuem pouco a renda deles advinda" (PDES-2015, 2015, p.26). Neste sentido, a terceira diretriz é contextualizada a partir de duas grandes orientações: "Uma primeira, com base no desenvolvimento de APL, dada a especificidade do tema e as particularidades do conjunto de ações e projetos necessários à sua estruturação, fortalecimento e implementação, e a segunda, abarcando os diversos setores da economia, voltada para o fomento de iniciativas e processos produtivos com potencial para 0 desenvolvimento sustentável" (PDES-2015, 2015, p.151). Portanto, em termos de concepção geral, o PDES está em consonância com a proposta de um novo paradigma de desenvolvimento que não implique em destruição da floresta, valorizando as formas produtivas alternativas. No entanto, esta visão deve estar refletida nos programas que compõem a diretriz em análise. Assim, foi verificada a presença dos fatores das categorias de análise nos referidos programas. 0 resultado consolidado para a perspectiva de curto prazo está expresso no quadro 3.

QUADRO 3 - CATEGORIAS DE ANÁlise dE CURTO PRAZO PRESENTES nOS PROGRAMAS

\begin{tabular}{|l|l|}
\multicolumn{1}{|c|}{ Categorias } & \multicolumn{1}{|c|}{$\begin{array}{c}\text { Programas com Presença de } \\
\text { Fatores de Análise }\end{array}$} \\
\hline $\begin{array}{l}\text { 1) Investimento e modificações nas estruturas sociais, econômicas e políticas } \\
\text { da valorização dos produtos da biodiversidade. }\end{array}$ & $1,4,611$ e 14 \\
\hline $\begin{array}{l}\text { 2) Incentivo e valorização dos produtos com baixo impacto no sistema } \\
\text { amazônico }\end{array}$ & $1,4,6,8,11$ e 14 \\
\hline 3) Benefícios para populações regionais & $1,4,11$ e 14 \\
\hline \multicolumn{1}{|c|}{ Fonte: Elaborado pelos autores }
\end{tabular}

Fonte: Elaborado pelos autores.

O programa 1 é essencialmente estratégico e possui como contexto a orientação ao Estado para "... selecionar aqueles que representam maior expressividade econômica, melhor potencial organizativo e programas de fomento a iniciativas e processos produtivos com potencial para 0 desenvolvimento sustentável" (PDES-2015, 2015, p.152). No entanto, não foi localizado projeto com capacidade de promover uma atuação sistêmica para promover desenvolvimento tecnológico, a inovação e o reconhecimento dos problemas da região e os indicadores selecionados não são adequados para mensurar o desenvolvimento sustentável da região. Contata-se que o PDES não inovou, mas delegou de forma genérica a responsabilidade de obrigação de elaborar programas e projetos para os APLs. Apesar deste fato, a análise dos objetivos e indicadores revelam a presença dos descritores em todas as categorias de análise em curto prazo, com ênfase nos seguintes: 1.4) aprimoramento na qualidade final dos produtos da biodiversidade; 1.5) aumento da identificação da variedade de produtos da biodiversidade e do potencial de exploração de cada um desses; 2.1) identificação dos impactos ambientais, econômicos e sociais da exploração dos produtos da sociobiodiversidade e da agricultura familiar e; 3.1) Impactos na qualidade de vida do sucesso na exploração destes produtos para a população local.

O programa 4 tem como foco o Fortalecimento da Agricultura Familiar, tratado no plano como prioridade, considerando que a produção familiar corresponde aproximadamente $70 \%$ dos alimentos consumidos no país. Neste programa existem dois objetivos específicos visando o seu fortalecimento e o apoio a agroecologia e produção orgânica. Em ambos os objetivos há reforço para participação do Estado, das Prefeituras Municipais, Sociedade Civil e dos próprios agricultores.

OS, Organizações e Sustentabilidade, 8(1), p. 124-140, Londrina, PR, jan./jun. 2020.

ISSN 2318-9223, http://www.uel.br/revistas/uel/index.php/ros/issue/view/1634/showToc 
Nos projetos também foi prevista a intervenção por meio de análise territorial. Os indicadores selecionados para apurar os resultados dos projetos abordam uma perspectiva multidisciplinar, envolvem diferentes atores e possuem metas específicas num viés quantitativo que vai além de números econômicos, abarcando a quantidade de produtores envolvidos com os produtos orgânicos e controle social dessa produção, projetos de pesquisa, redes de organização voltadas a agroecologia etc. Assim, neste programa da agricultura familiar é possível afirmar que há a presença dos fatores de todas as categorias para análise de curto prazo.

Pela análise do Programa de Apoio à Aquicultura (6), verifica-se nele a existência de 10 projetos para apoio ao desenvolvimento da atividade econômica voltada à cadeia produtiva da aquicultura, geração de empregos e aumento da qualidade dos produtos. 0 interesse pela pesquisa e pela conquista de selos de qualidade visando a exportação a outros estados e outros países é um dos potenciais de desenvolvimento dos produtores locais. A criação de peixes visando o atendimento do mercado interno e externo e a exploração da pesca esportiva são potenciais identificados pelo PDES para os produtores regionais que não conseguem atingir seus objetivos em razão dos gargalos presentes (PDES-2015, 2015). O desenvolvimento tecnológico para modificar a atual forma de exploração de produção e comercialização de pescados é fator de análise a partir da criação de três indicadores neste programa: elaboração de termos de cooperação técnica com as universidades e institutos de pesquisa, percentual de utilização de tecnologias inovadoras e número de profissionais atendidos. Desta forma e com base nos fatores de análise, verifica-se presença das categorias relacionadas ao 1) Investimento e modificações nas estruturas sociais, econômicas e políticas da valorização dos produtos da biodiversidade e 2) Incentivo e valorização dos produtos com baixo impacto no sistema amazônico. Tendo em vista a ausência de identificação de indicadores e programas específicos para apurar os impactos à comunidade local, não há presença sólida da categoria 3) Benefícios para populações regionais.

No programa 8, relacionado ao apoio à lavoura cacaueira, os indicadores escolhidos para avaliar seu desenvolvimento indicam interesse por uma cultura cacaueira sustentável mediante os projetos de diversificação de atividades nos estabelecimentos rurais e desenvolvimento de capacidade empresarial. Há reconhecimento do papel estratégico do poder público. No entanto, os projetos ficaram limitados a realizar um diagnóstico para reconhecer as alterações a serem efetuadas, deixando de contemplar ações para promover a alteração da situação atual. Por isso, constou-se apenas a presença dos fatores da categoria 2 (Incentivo e valorização dos produtos com baixo impacto no sistema amazônico) em função dos objetivos específicos do programa e não em razão dos projetos.

0 programa 11, dirigido ao fomento da cadeia da sociobiodiversidade, mediante atividades de organização dos extrativistas e da interação entre eles e a indústria, é composto por projetos de apoio às organizações de extrativistas com indicadores voltados para as metas que serão definidas após a realização dos estudos para definição das áreas prioritárias do Estado, a integração entre os extrativistas e indústria e ações institucionais para captação de investimento privado para o setor. Neste caso, foi possivel identificar descritores de todas as categorias de análise para o curto prazo. Importante destacar que os produtos da sociobiodiversidade estão relacionados com a economia da subsistência das comunidades em razão de serem localizados e produzidos nas unidades de conservação e amplamente aceitos no comércio local. Há reconhecimento da contribuição destes produtos na renda destas famílias (PDES-2015, 2015). A exploração dos produtos da biodiversidade foi eleita por Nobre, Sampaio, Borma, Castilla-Rubio, Silva \& Cardoso (2016) como uma forma de superar o paradigma atual a curto prazo, identificando ser possivel desenvolver uma cadeia de produtos únicos advindos da biodiversidade da Amazônia, com agregação de valor para conquistar o mercado.

OS, Organizações e Sustentabilidade, 8(1), p. 124-140, Londrina, PR, jan./jun. 2020. 
O programa 14, que trata da promoção da Cultura e Apoio ao Desenvolvimento da Economia Criativa, tem como enfoque o desenvolvimento socioeconômico a partir da valorização das culturas das pessoas que estão presentes na história da região rondoniense. Os projetos são voltados para a estruturação e fortalecimento do setor, promoção da cultura e desenvolvimento da economia criativa em si. São encontrados indicadores que demonstram o reconhecimento dos impactos da economia criativa para a região, bem como sobre a necessidade de instrumentos legais visando sua proteção e o financiamento público. Em Rondônia, assim como em toda a Amazônia, a diversidade cultural se coloca como um importante ativo socioeconômico. No momento de economia de escala global, com a ocorrência dos efeitos da globalização e massificação internacional da cultura, devese reconhecer a importância deste tipo de comércio e serviço para encontrar novos caminhos do desenvolvimento sustentável, não apenas na visão econômica, mas também nos benefícios de inovação em tecnologias criativas e benefícios sociais. Neste programa, podem ser identificados fatores de análise de todas as categorias em razão da proposta de aumento da identificação da variedade de produtos da biodiversidade e do potencial de exploração de cada um destes com base na cultura local, marketing nacional e internacional, capacidade comercial e produtiva de cada produto, na sua especificidade em razão do conhecimento cultural.

A promoção do turismo encontra-se prevista no programa 15, o qual pretende ampliar a economia rondoniense através das vertentes histórica, cultural e ambiental. Para tanto, 0 programa contará com projetos de identificação destas vertentes, ampliação da infraestrutura para acesso do público e implantação de centros, monumentos e pontos turísticos. Os estudos de impacto ambiental da atividade turística, a participação dos polos turísticos, a busca pelo incremento de turistas nacionais e estrangeiros podem constituir novas formas de desenvolvimento econômico e marketing da região rondoniense. Contudo, este programa não contempla como o desenvolvimento do turismo contribuirá para a competividade sustentável da região, com contribuições sociais, econômicas e ambientais. Desta forma, não há identificação de nenhum fator de análise.

O resultado consolidado para a perspectiva de longo prazo está expresso no quadro 4.

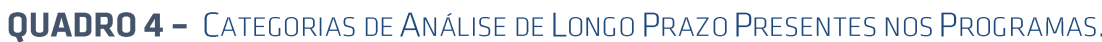

\begin{tabular}{|l|l|}
\multicolumn{1}{|c|}{ Categoria } & \multicolumn{1}{|c|}{\begin{tabular}{c}
\multicolumn{1}{|c|}{ Programas com Presença de Fatores de } \\
Análise
\end{tabular}} \\
\hline 1) Inovação com base em tecnologia & $2,3,5$ e 10 \\
\hline 2) Investimento de capital de risco. & 3,10 e 16 \\
\hline 3) Reformulação da produção baseada na integralidade da floresta. & $3,5,10$ e 12 \\
\hline \multicolumn{2}{|c|}{ Fonte: Elaborado pelos autores. }
\end{tabular}

Nos programas 2 e 3 de desenvolvimento da bovinocultura de corte e da bovinocultura de leite, respectivamente, foi identificado que "... os principais gargalos da atividade estão na organização da produção dos pequenos e médios produtores" (PDES-2015, 2015, p.154). Visando solucionar estas adversidades, sugeriu-se a aplicação do Manual de Boas Práticas Agropecuária, que destaca os aspectos de Cestão da propriedade rural, função social do imóvel rural, gestão dos recursos humanos, gestão ambiental, instalações rurais, manejo pré-abate, bem-estar animal, pastagens, suplementação alimentar, identificação animal, controle sanitário e manejo. A carteira deste programa é composta com três projetos voltados a elaboração de um termo de cooperação técnica. No programa de bovinocultura de leite (3), o objetivo final é aumentar a competitividade leiteira da região mediante modernização em todos os elos da cadeia produtiva. Para que o programa possa alcançar este objetivo, foram elaborados projetos que visam superar os gargalos identificados, sendo um dos maiores desafios a complexidade da cadeia produtiva em razão das diferentes necessidades de cada uma das fases desta rede. Existe um projeto com objetivos voltados a preservação dos recursos naturais, dois projetos com objetivos focados nos produtores, com

OS, Organizações e Sustentabilidade, 8(1), p. 124-140, Londrina, PR, jan./jun. 2020.

ISSN 2318-9223, http://www.uel.br/revistas/uel/index.php/ros/issue/view/1634/showToc 
indicadores voltados a quantificar número de organizações e cooperativas em funcionamento e compartilhamento de tanque de esfriamento de leite e participação de produtores nos cursos, e três projetos com objetivos voltados a produtividade e comércio do leite. As análises desses programas permitiram identificar a existência de fatores das três categorias de análise.

A análise do programa 5, sobre a Transição para a Agropecuária de Baixa Emissão de Carbono, indica a presença dos descritores das categorias de análise de longo prazo: 1) Inovação com base em tecnologia; e 3) Novos produtos baseados no aprendizado com a floresta. Este programa foi estruturado com dois projetos visando alcançar o objetivo de reduzir as emissões de gases de efeito estufa na agricultura, mediante "... melhora eficiência no uso de recursos naturais e aumentando a resiliência de sistemas produtivos e de comunidades rurais, possibilitando a adaptação do setor agropecuário às mudanças climáticas" (PDES-2015, 2015, p.161).

O programa 7 - apoio à lavoura cafeeira possui como objetivo geral o aumento da produção de café na região rondoniense e requer a expansão da área produtiva, renovação dos cafezais e ganhos de produtividade como os requisitos necessários para atingir o objetivo. Nos objetivos específicos do programa, há a presença do aumento de eficiência econômica, da rentabilidade da propriedade da capacidade do empresariado, bem como o desenvolvimento de práticas sustentáveis e cafés orgânicos, por fim, apresenta o objetivo específico de promoção e processos de comércio e indústria. Para atingir os objetivos o programa apresentou sete projetos que compreendem, majoritariamente, o aumento da capacidade produtiva visando ganhos econômicos. Assim, verificou-se que existe o interesse em adotar práticas sustentáveis já reconhecidas na área, porém sem projetar indicadores que visem a adoção de novos investimentos para novas práticas, o que leva a identificar fatores de apenas uma das categorias de análise (Reformulação da produção baseada na integralidade da floresta).

Em relação ao setor madeireiro, para fins de elevar a competividade, numa perspectiva de valorizar tanto a exploração empresarial como a comunitária, o PDES elaborou o programa de número 10, de Ordenamento e Fomento à sustentabilidade no setor madeireiro, contando com 13 objetivos específicos, 13 projetos e 33 indicadores para verificar e avaliar os objetivos e metas. Os objetivos visam promover a concessão florestal nas Florestas Estaduais e Nacionais, promover manejo florestal com a intenção de "... diversificar os produtos da floresta, madeireiros e não madeireiros, além do incentivo a atividades alternativas como a exploração da biotecnologia e o ecoturismo" (PDES-2015, 2015, p.172); fortalecimento nas áreas de logística, políticas de crédito, ações para desenvolver os programas de APL no setor de madeira, promoção de atividades nas áreas educacionais e de pesquisa, desenvolvimento da silvicultura e atividades de marketing e gestão visando o mercado nacional e internacional. São identificadas questões relacionadas ao investimento financeiro em pesquisa para o desenvolvimento comercial de tecnologias disruptivas, promoção de educação sobre as relações de capacidade e necessidade de produção e consumo, política do consumo sustentável, indicadores que possam mensurar a projeção futura dos impactos dos modelos atuais para o meio ambiente e sociedade local e pesquisas para aplicar as tecnologias digitais existentes para promover a aproximação das populações locais aos grandes centros nacionais e internacionais. Assim, é possivel afirmar que estão presentes os fatores das três categorias de análise.

A análise do PDES indicou que o setor da atividade industrial (programa 12) é composto por participação predominante das atividades de fabricação de produtos de madeira e produtos alimentícios, sendo pequenas e médias empresas com produção de bens de baixo valor agregado e reduzido conteúdo tecnológico. Foi criada uma carteira de 8 projetos específicos com objetivo de promover a difusão tecnológica e econômica da região, medindo esses projetos por meio da elaboração de estudos, número de projetos e pequenas e médias indústrias instaladas na região. Existem quatro projetos que visam apoiar setores específicos da indústria de transformação no

OS, Organizações e Sustentabilidade, 8(1), p. 124-140, Londrina, PR, jan./jun. 2020. 
Estado. Neste caso, foi possivel identificar fatores relacionados a uma categoria de análise: Reformulação da produção baseada na integralidade da floresta.

A análise do programa 13, Desenvolvimento e Consolidação do Setor Mineral, indica a preocupação com a exploração do produto e não dos impactos ambientais e sociais que eles causam, como é o caso da citação que diz respeito a ampliação das explorações, desde que atenda as regras legais e a possibilidade de valer-se da utilização dos minérios em áreas indígenas (PDES-2015, 2015). Um programa desta envergadura, que terá impactos na criação de legislação, deveria ter ações e indicadores voltados à pesquisa e desenvolvimento de novas tecnologias para ampliar a relação do mineral com a região de forma holística, e não apenas da relação dos minérios com a economia. Assim, não foram identificados fatores de análise de nenhuma categoria.

O Programa 9, de apoio ao fortalecimento da cadeia produtiva de soja, foi desenvolvido para alcançar o objetivo de promover atos governamentais restritos a melhorar o apoio logístico de armazenamento, transporte e comercialização da soja em âmbito estadual (PDES-2015, 2015). A produção agrícola de commodities, como é o caso da soja, são os produtos que causam impactos positivos no desenvolvimento do agronegócio nacional e, em contrapartida, impactos negativos sociais e ambientais. Os impactos sociais estão relacionados a necessidade de grandes espaços de terra para a produção da soja, a falta de campo produtivo para os demais produtos agrícolas reduz a capacidade de produção de alimentos tradicionais e a produção local dos pequenos agricultores. Nada obstante a identificação destes riscos, o PDES de Rondônia não primou por projetos que visem a redução, modificação ou novas tecnologias para a produção e cultivo da soja.

O último programa da diretriz considerada, Programa da infraestrutura logística de transportes (16), não possui objetivo geral nem objetivos específicos delimitados expressamente no PDES. Por se tratar de logística multimodal, este programa contempla os projetos relacionados a infraestrutura aeroportuária, ferroviária, portuária, e as malhas rodoviárias federal, estadual e municipal. Cada uma das áreas contará com um plano diretor específico e ações que visam a ampliação da utilização destes meios de transporte, como a ampliação e modernização de aeroportos em municípios do Estado, além da capital, um plano hidroviário estadual, estudos sobre um novo complexo portuário. Neste caso, o que se verifica é o interesse em ampliar e consolidar a forma atual de deslocamento na região, tida como um "corredor de passagem". Portanto, com base no fator de análise de investimento de recursos financeiros para desenvolver novos produtos sem aumentar a exploração dos recursos já utilizados para a atividade econômica, pode-se afirmar a presença da categoria 2) Investimento de capital de risco.

Assim, em termos gerais, é possivel reconhecer nos objetivos e projetos propostos dos programas da Terceira Diretriz a existência de incentivo a extração de bens consumíveis da região sem o interesse no aprendizado de como esses bens são naturalmente desenvolvidos e como o homem pode desenvolver novos designs a partir deles, o que não favorece colocar em prática um possível modelo de superação do paradigma no longo prazo. Para utilizar os avanços da Quarta Revolução Industrial é necessário que exista uma união e emprego de diferentes tecnologias, nas categorias física, digital e biológica. Os objetivos e projetos analisados na terceira diretriz do plano pouco enfrentam este desafio, especialmente no que tange a proteção e desenvolvimento da agricultura familiar, APLs e exploração dos produtos da biodiversidade. Ademais, verifica-se que não há interesse em desenvolver uma capacidade de desenvolvimento de processos miméticos da região, mas sim numa perspectiva majoritariamente extrativista. Apenas no programa de industrialização de produtos da sociobiodiversidade é que se verifica uma possivel relação da forma como os produtos são gerados pela natureza e como o homem pode aprender com elas. Nos demais programas, o que se verifica é um incentivo a extração com menos onerosidade à natureza, qualificando-a como sustentável, ou uma forma de desenvolver a infraestrutura local para ampliar

OS, Organizações e Sustentabilidade, 8(1), p. 124-140, Londrina, PR, jan./jun. 2020. 
as condições de exploração econômica dos produtos naturais com menor impacto negativo para a floresta.

\section{CONSIDERAÇÕES FINAIS}

Na Amazônia, os modelos atuais de impedimento ou restrição legal de atividade humana em áreas de proteção ambiental integral e o de exploração para o desenvolvimento do agronegócio e para geração de energia necessitam ser superados. Urge buscar um novo paradigma para desenvolvimento da região, que pode ser alcançado em longo prazo a partir da inserção das tecnologias disruptivas da Quarta Revolução Industrial que encontrarão novas soluções a partir do aprendizado com a natureza e designs aplicados especificamente para a floresta. Enquanto o longo prazo é trilhado, existe uma proposta para curto prazo: a valorização dos produtos da sociobiodiversidade, agregando valor aos produtos únicos da região. O Estado de Rondônia deve abarcar no seu planejamento a necessidade de superar a visão da realidade atual de como se reconhece enquanto Região Amazônica, para então conseguir desenvolver uma nova maneira de desenvolvimento, que, diferente de simples remanejamentos, deverá promover mudanças profundas na geração de riquezas, o que não foi verificado no plano estudado.

Nesta pesquisa foram analisados os instrumentos denominados programas, projetos e indicadores da Terceira Diretriz (Competividade Sustentável) do Plano de Desenvolvimento Estadual Sustentável de Rondônia (PDES), cuja vigência é de quinze anos, a contar de 2015. Pode-se afirmar que, ainda que o PDES tenha uma elaboração de projetos voltados para um desenvolvimento sustentável abarcando as esferas ambiental, social, econômica e cultural, os programas ainda repetem estruturas que reforçam o paradigma atual de visão da floresta tropical, uma visão de apropriação. Em razão desta visão, há fortalecimento de programas que repetem o que vem sendo feito nas últimas décadas, valendo-se da tecnologia como uma ferramenta na esfera da infraestrutura para aumentar a produção e não para modificar a estrutura de desenvolvimento. Para as mudanças em curto prazo, há poucos programas que tenham capacidade de agregar valor aos produtos da sociobiodiversidade a ponto de modificar o modelo atual de exploração destes produtos, o que demonstra que a floresta ainda é vista como geradora de produtos a serem extraídos e não como um ambiente que contém riquezas. Em termos de longo prazo, os resultados da pesquisa também indicam que existem poucos programas e projetos da terceira diretriz que seguem a proposta de novo paradigma, com base em tecnologias inovadoras e disruptivas advindas da Quarta Revolução Industrial para fins de superar os modelos de desenvolvimento.

Verificada essa postura de manutenção nos programas apresentados, sugere-se a alteração e a reformulação de alguns programas a partir de três grandes elementos. 0 primeiro deles relacionados aos projetos que visam agregar valores aos produtos da biomassa amazônica, reconhecida como um potencial de superação do paradigma em curto prazo, como um caminho a ser perseguido enquanto as novas tecnologias advindas da quarta revolução industrial não estão comercialmente desenvolvidas e aplicadas na região. 0 desenvolvimento de atividades de baixo impacto ambiental contribui especialmente para a população local e para o desenvolvimento regional, que precisa ser apurado no decurso de aplicação do PDES sob o risco de se chegar ao final e os resultados não serem os esperados. O segundo elemento, relacionado a projetos que visam alterar as estruturas e infraestruturas das atividades com maior impacto ambiental, como ampliar o aprendizado tecnológico em substituição a exploração dos recursos naturais. O desenvolvimento tecnológico, terceiro elemento, com a ênfase na busca por investimentos de capital de risco para o desenvolvimento de tecnologia decorrentes da Quarta Revolução Industrial. O domínio desta nova tecnologia permite a apresentação de novos designs e soluções que visem aprender com a floresta.

OS, Organizações e Sustentabilidade, 8(1), p. 124-140, Londrina, PR, jan./jun. 2020. 


\section{REFERÊNCIAS}

Bardin, L. (2004). Análise de conteúdo. Lisboa: Edições 70.

Becker, B. K. (2001). Revisão das políticas de ocupação da Amazônia: é possivel identificar modelos para projetar cenários? Parcerias Estratégicas, Belém PA, 12. Disponível em <http://www.ufpa.br/epdir/images/docs/paper28.pdf>.

FERREIRA, L. R., ARAÚJO, P. F.C. \& MARQUES, R. W. C. (2006). Avaliação de um projeto de desenvolvimento sustentável em Rondônia. Economia e Sociedade, Campinas, 15(2), 401-408. Disponivel em <https://periodicos.sbu.unicamp.br/ojs/index.php/ecos/article/view/8642914/0>.

Ferreira, L. V., Venticinque, E. \& Almeida, S. (2005). O desmatamento na Amazônia e a importância das áreas protegidas. Estud. Av., São Paulo, 19(53), 157-166. Disponivel em <http://www.scielo.br/scielo.php?script=sci_arttext\&pid=S0103-

40142005000100010\&lng=en\&nrm=iso>.

Iguarán, N. J. \& Hernández, O. R. (2016). Ecología Política y Biomímesis. La Disputa por la Sustentabilidad. Sierra, Carlos (org.). Memorias del simposio internacional de estudios biomiméticos. Universidad Nacional Abierta y a Distancia, 1, ISSN: 2590-8502. Disponivel em <http://hemeroteca.unad.edu.co/index.php/memorias/article/view/1880/2111>.

INPE. (2017). Taxas de desmatamento. Disponivel em <http://www.obt.inpe.br/prodes/dashboard/prodes-rates.html>.

Mozzato, A. R. \& Grzybovski, D. (2011). Análise de conteúdo como técnica de análise de dados qualitativos no campo da administração: potencial e desafios. Rev. adm. contemp., Curitiba, 15(4), 731-747. Disponivel em <http://www.scielo.br/scielo.php?script=sci_arttext\&pid=5141565552011000400010\&Ing=pt\&nrm=iso>.

Nascimento, C. P., Silva, M. \& Santos, C. (2014). A formação do espaço de Rondônia: uma análise do zoneamento ecológico econômico e do uso e cobertura da terra. Revista Geografar, 9(1), 117-141. Disponivel em <http://revistas.ufpr.br/geografar/article/view/33017>.

Nobre, C. A., Sampaio, G., Borma, L. S., Castilla-Rubio, J. C., Silva, J. S. \& Cardoso, M. (2016). Land use and climate change risks in the Amazon and the need for a novel sustainable development paradigm. Proc. Natl Acad. Sci., 113, 10759-10768. Disponivel em <http://www.pnas.org/content/113/39/10759>.

Nobre, C. A. (2008). Mudanças climáticas globais e o Brasil: por que devemos nos preocupar Plenarium, 5(5), 12-20. Disponivel em <http://bd.camara.gov.br/bd/handle/bdcamara/723>.

Ollaik, L. G. \& Medeiros, J. J. (2011). Instrumentos governamentais: reflexões para uma agenda de pesquisas sobre implementação de políticas públicas no Brasil. Rev. Adm. Pública [on-line], 45(6), 1943-1967. ISSN 0034-7612. Disponivel em: <http://dx.doi.org/10.1590/S003476122011000600015>.

PDES-2015. (2015). Plano de desenvolvimento estadual sustentável de Rondônia 2015-2030. Porto Velho: Governo do Estado de Rondônia. Disponivel em <http://www.sepog.ro.gov.br/Conteudo/Exibir/332>.

Pedrozo, E. Á., Silva, T. N. , Sato, S. A. da S. \& Oliveira, N. D. A. (2011). Produtos Florestais Não Madeiráveis (PFNMS): as filières do açaí e da Castanha da Amazônia. Revista de Administração e Negócios da Amazônia, 3(2). Disponivel em <http://www.periodicos.unir.br/index.php/rara/article/download/201/234>. 
Pedlowski, M. A., Dale, V. H., Matricardi, E. A.T. \& Silva Filho, E.P. (1997). Patterns and impacts of deforestation in Rondônia, Brazil. Landscape and Urban Planning, 38(3), 149-157. Disponivel em <http://www.uenf.br/Uenf/Downloads/P_SOCIAIS_3809_1161191161.pdf>.

Pedrini, A. G. (2006). A educação ambiental com a biodiversidade no Brasil: um ensaio. Ambiente $\mathcal{G}$ Educação, 11, 63-77. Disponivel em <https://periodicos.furg.br/ambeduc/article/download/768/265>.

Russo, S. L., Silva G. F. \& Nunes, M. A. S. N. (2012). Capacitação em Inovação Tecnológica para Empresários. São Cristóvão: Editora UFS.

Sachs, I. (2009). Caminhos para o desenvolvimento sustentável. 2. ed. São Paulo: Caramond, 2009. Schwab, K. (2016). A Quarta Revolução Industrial. Editora: Edipro.

Santana, V. O. (2007). Reservas extrativistas estaduais de Rondônia: uma história em construção. 147 f. Dissertação (mestrado) - Universidade Estadual Paulista, Faculdade de Filosofia e Ciências. Disponivel em <https://repositorio.unesp.br/handle/11449/96145>.

Sierra, C. (2016). Biomímesis: El Imaginario Instrumental de la Naturaleza en la Tecno-Ciencia Contemporánea. In: Sierra, Calos (org.). Memorias del simposio internacional de estudios biomiméticos. Organizador. Universidad Nacional Abierta y a Distancia, 1. ISSN: 2590-8502. Disponivel em <http://hemeroteca.unad.edu.co/index.php/memorias/article/view/1880/2111>.

Silva, L. E., Albuquerque, U. P. \& Amaral, W. (2017). Uso sustentável da biodiversidade e conservação de recursos naturais. Revista Brasileira de Desenvolvimento Territorial Sustentável. 3(1), 02-10. Disponivel em <http://revistas.ufpr.br/guaju/article/view/53845/32964>. 